\title{
LAS FAMILIAS INMIGRANTES EN ESPAÑA
}

\author{
IMMIGRANTS FAMILIES IN SPAIN
}

\author{
Miguel ReQUeNA mrequena@poli.uned.es \\ Universidad Nacional de Educación a Distancia y Grupo de Estudios "Población y Sociedad". España
}

María SÁnchez-Domínguez msanchez@geps.es

Universidad Complutense de Madrid y Grupo de Estudios "Población y Sociedad". España

\begin{abstract}
RESUMEN
El espectacular crecimiento de la inmigración internacional en España en los últimos años ha producido notables hallazgos sobre los comportamientos familiares de los inmigrantes asentados en nuestro país. Poco sabemos, sin embargo, de las formas familiares de convivencia de los inmigrantes o del proceso de reagrupación familiar. En este artículo nos proponemos suplir estas carencias a partir de los datos de la Encuesta Nacional de Inmigrantes 2007. Los principales objetivos de investigación son tres: las formas de convivencia de los inmigrantes desde el punto de vista del tamaño y la estructura de sus hogares; la composición de los hogares en términos de los familiares nucleares ausentes y presentes; y, los procesos de reagrupación familiar que han dado lugar a la configuración de esas estructuras domésticas. En concreto, analizamos los factores que promueven o impiden la reagrupación de los cónyuges y los hijos a los hogares de los inmigrantes ya asentados en España.
\end{abstract}

\section{Palabras Clave}

España, Familia, Inmigración, Reagrupación familiar.

\begin{abstract}
The dramatic growth of international immigration in Spain in recent years has inspired a large literature concerning the major family practices of immigrants settled in Spain. However, little is known about the familial forms of coexistence of immigrants or the process of family reunification. This article intends to address these shortcomings with data from the National Survey of Immigrants 2007. We propose three main research objectives. First, the forms of co-residence of immigrants from the standpoint of size and structure of their homes. Second, the composition of households in terms of nuclear family members absent and present. Finally, the family reunification processes that led to the configuration of these domestic structures. In particular, we analyze the factors that promote or hinder reunification of immigrants with their spouse and children in Spain.
\end{abstract}

\section{KEYWORDS}

Family, Family Reunification, Immigration, Spain 


\section{INTRODUCCIÓN}

Entre los estudiosos del fenómeno de las migraciones hay un acuerdo sustancial en la tesis de que los movimientos migratorios tienen siempre una dimensión esencialmente familiar. Muy a menudo, las migraciones nacen en el seno de unidades familiares, se acomodan a los ciclos vitales de las familias, descomponen las estructuras domésticas de convivencia en las que se originan y terminan contribuyendo a la formación de nuevos hogares. Un conocido especialista ha señalado, en este sentido, que los procesos migratorios son, básicamente, un asunto de familia y que la familia debe ser, en consecuencia, un foco de investigación estratégico del análisis de las migraciones (Rumbaut 1997). La propia idea de las cadenas migratorias, de tanto éxito académico en los últimos años, presupone de alguna manera el contexto familiar de los movimientos migratorios, pues es sabido que las redes sociales en las que se inscriben tales procesos suelen ser de naturaleza familiar: los inmigrantes forman, por lo general, parte de una cadena o red que enlaza a los familiares en los países de origen con los familiares en los países de destino y por la que circulan los recursos de todo tipo de los que éstos se valen para mitigar las dificultades asociadas al traslado, instalación y subsistencia en los países receptores. Ello es así al punto de que el encadenamiento familiar produce un efecto multiplicador del fenómeno de la inmigración (Jasso y Rosenzweig 1986; Massey 1987) y la reagrupación familiar constituye, en todos los países que ya han alcanzado un cierto volumen de población inmigrada, uno de los motores principales de sus nuevos flujos migratorios (Kofman 2004).

Las dinámicas migratorias son, así, en muy buena medida, familiares: las primeras no se pueden entender propiamente sin las segundas. Dos aspectos de estas dinámicas son de interés analítico aquí. De una parte, la familia desempeña un papel central en los procesos migratorios porque es la unidad social elemental en la que se produce la decisión de emigrar, decisión que en no pocas ocasiones se toma, además, con criterios, perspectivas y objetivos específicamente familiares (Borjas y Bronars 1991). De otra, el propio proceso migratorio supone, salvo en los raros casos en los que es el grupo doméstico el que acomete la empresa migratoria de forma conjunta y simultánea, una necesaria ruptura de la unidad familiar de origen que, eventualmente, puede llegar a recomponerse total o parcialmente en la sociedad de destino.

Es sabido, en efecto, que los movimientos migratorios se producen por lo general paso a paso (Suárez-Orozco, Todorova y Louie 2002), con un pionero que suele abrir el camino a la llegada posterior de los familiares a los que, si tiene éxito en su destino migratorio, consigue agrupar de nuevo. No es menos conocido que esta obligada y a veces dolorosa separación física de la unidad familiar, así como la consiguiente interrupción de los vínculos y relaciones familiares más próximos, supone altos costes emocionales y de otro tipo para los emigrantes (Falicov 2008; Pedone y Gil 2008). El propósito de minimizar o acabar con esos costes empuja a muchos inmigrantes a procurar lo antes posible la reunificación de los familiares más cercanos - en lo fundamental, pareja, hijos y padres-, aunque la reagrupación requiere algún tiempo y un cierto grado de integra- 
ción del pionero en la sociedad de acogida ${ }^{1}$. En cualquier caso, en la medida en que la reunificación familiar disminuye las múltiples tensiones asociadas a la separación, es también un medio de facilitar la integración de los inmigrantes (Fix, Zimmermann y Passel 2001) y por ello se ha convertido en un objetivo importante de las políticas públicas migratorias en los países receptores (González 2007).

Siendo el objeto del presente trabajo las familias inmigrantes instaladas en España, nuestra propuesta se centra en ese segundo aspecto de la dinámica familiar de los movimientos migratorios: la formación y las características de los hogares inmigrantes en la sociedad de destino, los posibles déficit de familiares en la composición de estos hogares y los movimientos de reagrupación familiar que tratan de compensarlos y anularlos. Con esta propuesta, y mediante la explotación de las nuevas bases de datos ahora disponibles en nuestro país, pretendemos cubrir un importante hueco en la investigación del fenómeno migratorio en la sociedad española que hasta el momento no ha recibido, en nuestra opinión, la atención que merece.

En efecto, la masiva y rápida afluencia de inmigrantes que ha experimentado en los últimos años la sociedad española (Arango 2004; Garrido 2005; Reher y Requena 2009b) ha producido ya un notable cuerpo de investigación en torno a los comportamientos familiares de la población inmigrada que aborda algunos de sus más importantes aspectos. Así, han sido ya tratados con cierto detalle sus comportamientos reproductivos (López de Lera 2006; Roig y Castro 2007), sus pautas de emparejamiento (Cabré, Cortina y Esteve 2009; Cortina, Esteve y Domingo 2006; Cortina, Esteve y Domingo, 2008; Esteve y Cortina, 2009) o el apoyo que les brindan las redes de parentesco (Pascual, 2007). Disponemos asimismo de diferentes estudios que se circunscriben al ámbito local 0 a la concreta realidad de los inmigrantes de un determinado origen nacional, regional o cultural. Escasean, sin embargo, los estudios de conjunto sobre las pautas de convivencia y las formas familiares de los inmigrantes en España (Reher et al., 2008; Instituto Nacional de Estadística 2009) o los análisis generales dedicados específicamente a la reagrupación familiar (González 2008).

Con objeto de suplir estas carencias, y recurriendo a la nueva base de datos sobre la inmigración en España que nos suministra la Encuesta Nacional de Inmigrantes 2007, en este trabajo nos proponemos estudiar desde una perspectiva amplia, exhaustiva e integral las formas familiares de convivencia de los inmigrantes asentados en España. Puesto que, hasta donde sabemos, este tipo de análisis sobre las familias inmigrantes no se ha desarrollado aún en nuestro país, nuestro trabajo tendrá un carácter eminentemente exploratorio, pero no por ello menos necesario dada la carencia de información sistemática y general sobre nuestro objeto de investigación. Tras describir sumariamente la base de datos que vamos a utilizar y las características elementales de los inmigran-

\footnotetext{
${ }^{1}$ De hecho, la regulación jurídica de la reagrupación familiar suele exigir que el reagrupante haya completado un cierto periodo mínimo de residencia en el país de destino y acredite que dispone de medios para atender a los familiares reagrupados (González 2007).
} 
tes que estudiamos, procedemos al análisis del tamaño y la estructura de los hogares inmigrantes, de su composición en términos de los familiares presentes y ausentes en ellos y de la dinámica de reagrupación familiar que impulsan. Por último, presentamos las principales conclusiones de nuestro análisis.

\section{FuENTES, DATOS Y CARACTERÍSTICAS BÁSICAS}

Nuestro estudio se basa en los datos procedentes de la Encuesta Nacional de Inmigrantes 2007 (en adelante, ENI 2007) realizada entre noviembre de 2006 y febrero de $2007^{2}$. Contiene información sobre un total de 15.465 entrevistas realizadas a inmigrantes de 16 y más años que llevaban residiendo en España al menos un año ${ }^{3}$. Por otro lado, la encuesta proporciona información sobre 17.700 hogares en los que al menos uno de sus miembros cumple con las características anteriores. En este trabajo empleamos datos ponderados $y$, salvo cuando se indica lo contrario, elevados, por lo que la cifra total de inmigrantes asciende a 4.526.522 y la de hogares a 2.158.694.

La ENI 2007 nos provee de información suficiente para analizar no sólo las características de los núcleos familiares de los inmigrantes asentados en nuestro país, sino también los rasgos definitorios de las familias transnacionales y el funcionamiento de los procesos de reagrupación familiar en España. Estas características y dinámicas de los procesos familiares pueden ser puestas en relación con las características demográficas y socioeconómicas de los inmigrantes encuestados en la ENI 2007 (Reher y Requena 2009a).

Gran parte de los análisis que presentamos en este trabajo se basan en una tipología de inmigrantes que se compone de cuatro categorías: españoles de nacimiento, jubilados, profesionales e inmigrantes económicos (Requena y Reher 2009). La tabla 1 muestra su distribución y sus principales características sociodemográficas y familiares.

Los españoles de nacimiento se definen como aquellos inmigrantes que, aun habiendo naciendo fuera de España, llegaron a nuestro país con más de dos años de edad y tienen la nacionalidad española desde el nacimiento. Los dos ejemplos que mejor representan esta categoría son algunos de los inmigrantes procedentes de Marruecos y de Argentina, ambos con fuertes vínculos históricos con España (Cebolla y Requena 2009; Reher y Sánchez Alonso 2009). Hemos diferenciado este grupo, segundo de los cuatro en importancia numérica, con el fin de controlar la posible inconsistencia analítica que implicaría considerar como inmigrantes a españoles que, aunque nacieron fuera de España por diversas razones, han residido en nuestro país la mayor parte de su ciclo

\footnotetext{
${ }^{2}$ La fecha de referencia de la Encuesta Nacional de Inmigrantes 2007 es el 1 de enero de 2007.

${ }^{3}$ En el caso de que los encuestados no cumplieran el requisito de llevar un año residiendo en España, tenían que manifestar la intención de hacerlo.
} 
Tabla 1.

Características demográficas y familiares de los inmigrantes en España (2007)

\begin{tabular}{|c|c|c|c|c|c|c|}
\hline & $\mathrm{N}$ & $\%$ & Edad media* & Estancic & a en España (años) & Sex ratio \\
\hline Españoles de nacimiento & 266.700 & 5,9 & 44,7 & & 34,7 & 115,4 \\
\hline Jubilados & 167.359 & 3,7 & 72,4 & & 21,0 & 99,6 \\
\hline Profesionales & 248.396 & 5,5 & 40,6 & & 13,5 & 143,8 \\
\hline Inmigrantes económicos & 3.844 .067 & 84,9 & 36,4 & & 8,8 & 107,5 \\
\hline \multirow[t]{2}{*}{ Total } & 4.526 .522 & 100 & 38,4 & & 11,0 & 109,2 \\
\hline & $\%$ Solteros & $\%$ casados & s \% Separ. & + Divorc. & $\%$ Cohabitantes & $\mathrm{TMH}$ \\
\hline Españoles de nacimiento & 27,0 & 57,4 & 4,3 & & 6,1 & 3,12 \\
\hline Jubilados & 3,1 & 70,8 & 7,4 & & 3,2 & 2,17 \\
\hline Profesionales & 20,4 & 58,2 & 5,3 & & 14,4 & 2,84 \\
\hline Inmigrantes económicos & 26,9 & 50,7 & 4,7 & & 15,5 & 3,60 \\
\hline Total & 25,7 & 52,3 & 4,8 & & 14,5 & 3,40 \\
\hline
\end{tabular}

Fuente: Encuesta Nacional de inmigrantes 2007. * Población de 16 años o más.

vital. De hecho, se puede esperar que tanto las pautas de formación de hogares de este tipo de inmigrantes como las características propias de sus núcleos familiares sean las propias de los españoles, y no las de otros tipos de inmigrantes residentes en el país. El promedio de años de estancia en España de este tipo de inmigrantes, que asciende a 35 años, y la propia edad media del colectivo (45 años) sugieren una gran similitud con la población autóctona.

El segundo tipo lo integran los jubilados. Este grupo, el más importante numéricamente en España hasta la década de los noventa (Blanco 2000) y el de menor representación en nuestros días, se compone fundamentalmente de comunitarios oriundos de países del centro y norte europeo. Las características de este colectivo distan mucho de las del resto de los colectivos de inmigrantes aquí considerados. Son una población senescente que procede de países desarrollados cuyo proceso migratorio suele ser de carácter cíclico, ya que muchos de ellos sólo residen en España cortos períodos de tiempo, principalmente en la costa levantina y las islas, durante los meses estivales.

El tercer tipo, mayoritariamente masculino, es el de los profesionales, que se define por su alto nivel de capital humano (todos tienen estudios universitarios) y por ocupar empleos de alta cualificación. Se trata de profesionales, empresarios y directivos que desempeñan puestos de trabajo situados en la zona más alta de la pirámide ocupacional. Con un alto nivel de renta, comparten las suficientes características socioculturales con la población nativa como para no plantear mayores problemas de integración en la sociedad receptora. 
Por último, el principal colectivo de inmigrantes en nuestro país (85\% sobre el total de inmigrantes, en torno a los 3,8 millones de personas) viene representado por lo que tradicionalmente se conoce como inmigrantes económicos. Son una población joven que ha llegado a España recientemente y que se encuentra empleada en puestos de trabajo de baja cualificación. Proceden de forma muy mayoritaria de países en desarrollo, básicamente de la zona andina, África y el Este de Europa.

En líneas generales, las características familiares básicas de estos cuatro tipos de inmigrantes presentan particularidades propias de cada tipo. Como media, cinco de cada diez inmigrantes residentes en España están casados, aunque los jubilados lo están en razón de siete de cada diez; por otra parte, uno de cada cuatro está soltero y uno de cada siete forma parte de una unión de hecho. El fenómeno de la cohabitación se da, sobre todo, entre los inmigrantes profesionales y entre los económicos. En la difusión de la cohabitación entre los inmigrantes económicos pesa, sin duda, la creciente importancia de los flujos migratorios procedentes de los países latinoamericanos, donde sabemos que las uniones consensuales son una realidad muy extendida ${ }^{4}$.

El tamaño medio de los hogares subraya esta relativa heterogeneidad en las pautas de convivencia de los distintos tipos de inmigrantes. Los inmigrantes económicos son el tipo de inmigrantes que viven en los hogares más numerosos. En el otro extremo se sitúan los hogares en los que residen los jubilados. En una situación intermedia se encuentran los inmigrantes con nacionalidad española desde el nacimiento y los profesionales. Como veremos con más detalle a continuación, uno de los factores explicativos de esta heterogeneidad es la propia estructura de edad de los distintos tipos de inmigrantes aquí considerados. Los inmigrantes con nacionalidad española desde el nacimiento, los profesionales y lo inmigrantes económicos (los más jóvenes de los tres) se encuentran en la fase adulta del ciclo vital, como muestran sus respectivas edades medias. Es de esperar, por tanto, que tanto sus procesos de formación familiar como sus comportamientos reproductivos difieran sustancialmente de los jubilados, que se encuentran en la última fase del ciclo vital.

\section{TAMAÑO Y TIPOS DE HOGARES}

Los hogares de los inmigrantes asentados en España tienen, en principio, dos características básicas que los distinguen netamente de los hogares constituidos por la población autóctona de la sociedad receptora. De un lado, se trata de hogares más numerosos que los de los españoles; de otro, son hogares que contienen también más complejidad interna, en el sentido de que albergan una mayor densidad de relaciones domésticas, familiares y no familiares, en su seno.

\footnotetext{
${ }^{4}$ En muchos países de América Latina las uniones consensuales llegan a superar a las uniones de derecho entre las mujeres que están en edad reproductiva (Castro 2002).
} 
Por lo que se refiere a la primera característica, la ENI estimó que existían en España a comienzos de 2007 un total de 2,16 millones de hogares en los cuales vivían inmigrantes. El tamaño medio de estos hogares era de 3,4 miembros. Puesto que la ENI no ofrece una muestra comparable de la población autóctona española, es preciso acudir a otras fuentes para perfilar la comparación con la sociedad de acogida. Los datos de la Encuesta de Población Activa (EPA) registran un tamaño medio del hogar (TMH) en España de 2,8 miembros en el primer trimestre del año 2007. En ese mismo trimestre, los hogares con persona de referencia nacida en España contenían en promedio 2,76 personas, mientras aquellos otros con persona de referencia nacida fuera de España presentaban un tamaño promedio de 3,09 personas. Para valorar en su justa medida este mayor tamaño de los hogares inmigrantes en España hay que ponerlo en relación, además, con la continua reducción del tamaño de los hogares españoles que se ha producido en los últimos años: la serie de datos de la EPA —la fuente más amplia en nuestro país para estimar el tamaño de los hogares en los periodos intercensales- refleja una disminución sostenida del tamaño de los hogares españoles en los diez últimos años que viene a prolongar una tendencia patente desde al menos los primeros años sesenta del siglo pasado (Requena 1999; 2004; 2009). Los hogares de los inmigrantes son así

Gráfico 1.

Distribución de hogares y personas por tamaño del hogar y tipo de inmigrantes

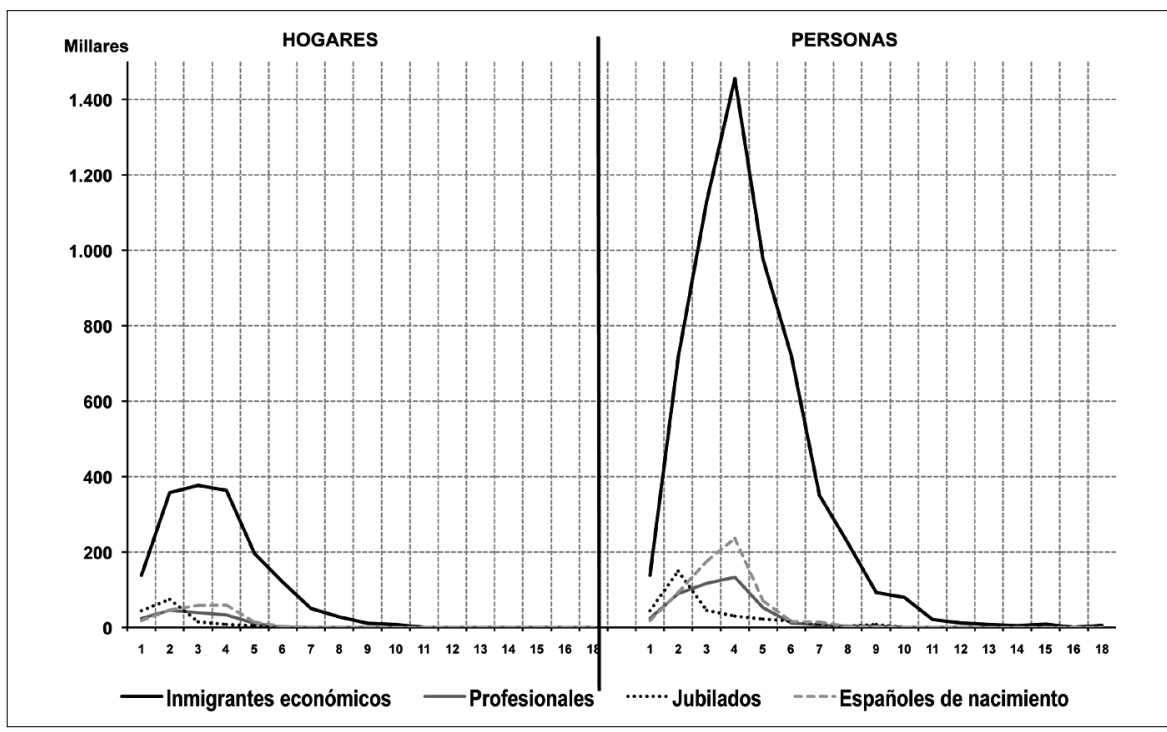

Fuente: Encuesta Nacional de Inmigrantes 2007. 
más numerosos que los de los españoles y se equiparan por su tamaño a los que eran típicos en España hace unos años.

El grado de concentración doméstica de los inmigrantes se pone de manifiesto con claridad en la distribución de los hogares en función de su tamaño. Los dos paneles del gráfico 1 muestran dicha distribución para los propios hogares y las personas. Entre el grueso de los inmigrantes (los inmigrantes económicos), el hogar típico es el de tres personas, siendo también muy numerosos los hogares integrados por dos y cuatro personas (en conjunto, los hogares de estos tres tamaños representan casi el $70 \%$ de todos los hogares); los hogares unipersonales suponen una décima parte del total y los hogares de más de cuatro miembros, una quinta parte. En cuanto a la distribución de las personas en los hogares de distintos tamaños (panel derecho del gráfico), los hogares típicos son los de cuatro miembros, en los que vive la cuarta parte de estos inmigrantes; en hogares de cinco miembros vive aproximadamente la misma proporción de inmigrantes (15\%) que en los de dos miembros (14\%); y sólo un escaso $3 \%$ de estos inmigrantes económicos vive en hogares unipersonales.

Como ponen de relieve los datos presentados en la tabla 1, los inmigrantes económicos son el tipo de inmigrantes que vive en los hogares más numerosos (3,60 miembros): superan en tamaño a los de los inmigrantes con nacionalidad española desde el nacimiento $(3,12)$, a los de los profesionales $(2,84)$ y a los de los jubilados $(2,17)$. Las distribuciones de hogares y personas por tamaño del hogar de estos distintos tipos de inmigrantes dibujan con claridad estos diferentes grados de concentración doméstica: el hogar tipo en el que viven más inmigrantes jubilados es el de dos personas, mientras que tanto en el caso de los profesionales como de los españoles de nacimiento es el de cuatro personas (gráfico 1). La distribución de personas en los hogares de distintos tamaños da cuenta, igualmente, de esa diferente propensión a la concentración doméstica de los cuatro tipos de inmigrantes que hemos distinguido.

Por lo que se refiere a la segunda de las características mencionadas, la composición de los hogares suele mantener una cierta correspondencia (no siempre estricta) con su tamaño. Por ello no debe extrañar que las pautas de co-residencia de los inmigrantes implícitas en el tamaño de sus hogares se relacionen con unas estructuras de convivencia que reflejan, ante todo, una propensión mayor a residir en hogares de composición relativamente compleja (tabla 2). Para el conjunto de los inmigrantes, encontramos unas proporciones, por ejemplo, de hogares constituidos por varias parejas con y sin hijos, de hogares monoparentales, de hogares sin núcleo y de parejas con hijos ligeramente superiores a las de los hogares españoles; por el contrario, la proporción de hogares unipersonales es sensiblemente menor entre los inmigrantes que entre los nacionales (véase Requena 2004 y 2009 para los datos españoles con los que establecer la comparación). 
Tabla 2.

Tipo de hogar según el tipo de inmigrantes ${ }^{5}$

\begin{tabular}{lccccr}
\hline & $\begin{array}{c}\text { Españoles de } \\
\text { nacimiento }\end{array}$ & Jubilados & Profesionales & Económicos & Total \\
\hline Una persona & 8,9 & 28,1 & 14,9 & 9,2 & 10,4 \\
Sin núcleo & 0,8 & 1,7 & 4,8 & 10,3 & 8,6 \\
Monoparentales & 11,8 & 2,9 & 8,3 & 9,4 & 9,3 \\
Pareja sin hijos & 15,9 & 51,8 & 22,7 & 19,1 & 20,5 \\
Pareja con hijos & 61,2 & 14,3 & 48,0 & 45,3 & 45,6 \\
Varias parejas con y sin hijos & 1,4 & 1,2 & 1,3 & 6,8 & 5,7 \\
Total & 100 & 100 & 100 & 100 & 100 \\
\hline
\end{tabular}

Fuente: Encuesta Nacional de inmigrantes 2007.

Ahora bien, las pautas de convivencia de los distintos tipos de inmigrantes ${ }^{6}$ en sus varias estructuras co-residenciales apuntan, en primer término, a la estructura de edad de cada tipo como un factor clave. El predominio de las edades avanzadas entre los jubilados explica la abultada proporción de hogares unipersonales y de parejas sin hijos; el perfil de edad de los inmigrantes con nacionalidad española desde el nacimiento y los profesionales sitúa a muchos de ellos en la fase adulta del ciclo vital y, por tanto, viviendo sobre todo en hogares constituidos por parejas con hijos, aunque debe subrayarse también la esperable incidencia de los hogares unipersonales entre los inmigrantes profesionales; los inmigrantes típicamente económicos, los más jóvenes de los cuatro tipos, cuya forma de convivencia más común es el hogar compuesto de pareja con hijos, destacan también por residir en mayor medida que el resto en hogares sin núcleo familiar y en los compuestos por varias parejas con y sin hijos. ${ }^{7}$

Este mayor grado de concentración doméstica de los extranjeros es muy notable, en el sentido de que el propio proceso migratorio implica, las más de las veces, la ruptura de los grupos familiares de origen de los inmigrantes. Es decir, excepto en aquellos casos en que es la familia la que emigra en bloque, el movimiento migratorio supone una división, si quiera transitoria, de la unidad familiar de convivencia de la que se procede.

\footnotetext{
${ }^{5}$ Respecto a los diferentes hogares de la tipología hay que advertir que los monoparentales son todos aquellos que se ajustan a la forma de un progenitor con algún hijo conviviente, con independencia de su edad; en las parejas con y sin hijos se incluyen todas, también con independencia de las edades de sus miembros. Es importante recordar también que la Encuesta se realizó a hogares, por lo que los alojamientos colectivos, en sus diferentes modalidades, quedan excluidos.

${ }^{6}$ Para las diferencias por origen nacional, véase Reher et al. (2008).

${ }^{7}$ Como es de esperar, este tipo de hogares son por término medio los más numerosos de los que aquí consideramos: 5,9 miembros (Reher et al. 2008).
} 
Se podría esperar, entonces, que los hogares de los inmigrantes fueran más pequeños y más simples que los de los nacionales; al menos, hasta que hubiera transcurrido el tiempo suficiente para permitir los movimientos de reagrupación familiar o de formación de nuevas unidades familiares en el país de destino. Ahora bien, tanto la reagrupación familiar como la formación de nuevas unidades familiares son procesos que implican recursos cuya consecución requiere, ante todo, tiempo. Por ello, en un país con una experiencia migratoria tan reciente como la de España, el mayor tamaño y la estructura relativamente compleja de los hogares de los inmigrantes tienen algo de paradójico.

¿Son los procesos de reagrupación familiar o la rápida formación de nuevas unidades familiares en España los factores responsables del tamaño (relativamente alto) y la estructura (relativamente compleja) de sus hogares inmigrantes? Como es obvio, tanto la reagrupación familiar como la formación de nuevas unidades familiares - con una fecundidad superior a la de las parejas españolas (López de Lera 2006; Roig y Castro 2007) - son procesos que hacen aumentar de tamaño los hogares de los inmigrantes. Sin embargo, no son los únicos. Como se sabe, la estrecha asociación entre los movimientos migratorios y las redes sociales en que se inscriben (Massey y Phillips 1999; Massey, Durand y Riosmena 2006) dotan a los inmigrantes -en particular a los recién llegados a sus destinos- de oportunidades materiales y relacionales que a la postre vienen a resultar imprescindibles para hacer viable el propio movimiento migratorio: por ejemplo, son las propias cadenas migratorias las que suministran a los inmigrantes las condiciones básicas de alojamiento en el país de destino impulsando la formación de estructuras domésticas relativamente amplias, pues como se ha señalado (Izquierdo 2003; Pascual 2007) los lazos fuertes y en especial los familiares son cruciales en la fase de instalación en el país receptor. ${ }^{8}$ Aunque la incorporación del inmigrante a un hogar ya constituido en la sociedad receptora no reproduzca de inmediato la estructura familiar de la que procedía en su país de origen, la propia red migratoria en la que se inserta su movimiento lo suele llevar a unirse a un hogar ya formado por parientes o conocidos suyos, lo que incrementa su tamaño y añade complejidad relacional al mismo. Numerosos estudios han verificado que los inmigrantes tienden a convivir con miembros de su familia extensa en estructuras domésticas relativamente complejas (véase, por ejemplo, Van Hook y Glick 2007 y la literatura que citan).

\footnotetext{
${ }^{8}$ Según datos de la ENI 2007, siete de cada diez inmigrantes de los que tenían alguien a quien acudir cuando llegaron a España, contaban con familiares a los que dirigirse.
} 
Tabla 3.

Tamaño medio de los hogares en los que viven inmigrantes según tipo de hogar y de inmigrante

\begin{tabular}{lccc}
\hline & Todos & $\begin{array}{c}\text { Todos los miembros } \\
\text { nacidos fuera de España }\end{array}$ & $\begin{array}{c}\text { Miembros nacidos } \\
\text { en España }\end{array}$ \\
\hline Españoles de nacimiento & 3,12 & 1,39 & 3,37 \\
Jubilados & 2,17 & 1,76 & 2,91 \\
Profesionales & 2,84 & 2,06 & 3,23 \\
Económicos & 3,60 & 3,37 & 3,83 \\
Total & 3,40 & 3,10 & 3,66 \\
Porcentaje de hogares & $100 \%$ & $46,6 \%$ & $53,4 \%$ \\
\hline
\end{tabular}

Fuente: Encuesta Nacional de inmigrantes 2007.

De particular importancia a este respecto es el proceso de incorporación de los inmigrantes a hogares en los que conviven con la población autóctona. Según los datos de la ENI 2007 que se presentan en la tabla 3, en más de la mitad (53,4\%) de los hogares en los que vivían inmigrantes, éstos convivían con alguna persona nacida en España. Y, lo que es más importante, estos hogares mixtos en los que conviven nacidos en España y en otros países tienen un tamaño superior $(3,66)$ al de los hogares integrados sólo por individuos nacidos fuera de España $(3,10)$. Por lo tanto, la co-residencia con la población autóctona explica en buena medida una parte del gran tamaño de los hogares en los que viven los inmigrantes en España. En realidad, si se tienen en cuenta los distintos tipos de inmigrantes, el tamaño de los hogares en los que viven (sin otros miembros nacidos en España) los inmigrantes con nacionalidad española desde el nacimiento, los jubilados y los profesionales es muy reducido, siempre inferior al del conjunto de los hogares españoles. Sólo los inmigrantes económicos (que no conviven en hogares mixtos con personas nacidas en España) registran un tamaño medio del hogar relativamente alto (3,37 miembros).

Nótese que esta estimación de la ENI 2007 del tamaño de los hogares integrados exclusivamente por inmigrantes $(3,10)$ es muy similar a la que proporciona la EPA (primer trimestre de 2007) para los hogares cuya persona de referencia ha nacido fuera de España (3,09 miembros por hogar). A lo que podemos añadir ahora que ese tamaño promedio de los hogares inmigrantes está sustancialmente afectado por la estructura de edad de su población. En efecto, una simple simulación con datos de la EPA del tamaño promedio de los hogares de las personas de referencia nacidas fuera de España, suponiendo que tuvieran la misma estructura de edades que las personas de referencia nacidas en España, genera un hogar medio de 2,80 miembros (en lugar de los 3,09 realmente observados); es decir, un tamaño muy próximo al del conjunto de los hogares 
españoles $(2,76){ }^{9}$ Por lo tanto, una gran parte de la diferencia entre las estructuras de convivencia doméstica de ambas poblaciones - autóctonos e inmigrantes- parece que obedece a un mero efecto de composición. De hecho, si excluimos a los inmigrantes que conviven con españoles, las pautas de co-residencia de los inmigrantes no son tan distintas de las de la población autóctona, excepto por lo que se refiere a las diferencias que se derivan de la estructura de edad de la propia población inmigrante.

En suma, las dos características básicas de los hogares de los inmigrantes asentados en España - su elevado tamaño y su alto grado relativo de complejidad - deben explicarse por: (a) su asociación doméstica con la población autóctona; (b) por la inserción en redes sociales que facilitan su instalación y alojamiento en España y les empujan a incorporarse a hogares ya formados de parientes y conocidos; y (c) por la contribución de los movimientos de reagrupación familiar que tratan de reconstruir las unidades familiares que se dividieron con ocasión del traslado migratorio.

\section{FAMILIARES PRESENTES Y AUSENTES EN LOS HOGARES INMIGRANTES}

Las pautas de convivencia doméstica de los inmigrantes que acabamos de examinar nos proporcionan una primera aproximación a la realidad de los familiares ausentes y presentes en sus hogares. Como hemos visto, siete de cada diez de sus hogares están integrados por parejas (con o sin hijos); en los tres restantes residen personas solas, grupos domésticos que no incluyen un núcleo familiar o núcleos de alguna manera incompletos. Sin embargo, esta información relativa a las formas de convivencia es insuficiente para evaluar la situación familiar de los inmigrantes y la influencia de los procesos de reunificación en sus hogares. Al objeto de perfilarlas con la debida precisión, es recomendable analizar ahora por separado, y desde la perspectiva de los individuos, la situación de los inmigrantes respecto a sus cónyuges, hijos y padres, pues ellos son el tipo de familiares que constituyen el objeto del grueso de los movimientos de reunificación familiar que tienen un impacto potencial mayor en la estructura de los hogares.

Como hemos tenido oportunidad de observar ya (tabla 1 ), del total de los 4,5 millones de inmigrantes asentados en España a comienzos del año 2007 en torno a 2,365 millones $(52,3 \%)$ estaban casados. A éstos hay que sumar en torno a 650 mil más $(14,5 \%)$ que cohabitaban con sus parejas sin estar casados. A su vez, de los inmigrantes casados, casi nueve de cada diez (2,08 millones) convivían con sus cónyuges, es decir, habían emigrado de forma simultánea, habían contraído matrimonio en España o se habian reagrupado. Frente a ellos, una cifra próxima a los 285 mil inmigrantes estaban casados pero vivían sin su cónyuge y, por lo tanto, eran reagrupantes potenciales.

\footnotetext{
${ }^{9}$ Aquí no se presentan los datos de la simulación que están, sin embargo, a disposición de cualquier lector que se los requiera a los autores.
} 


\section{Gráfico 2}

Situación de pareja de los inmigrantes casados por tipo de inmigrantes

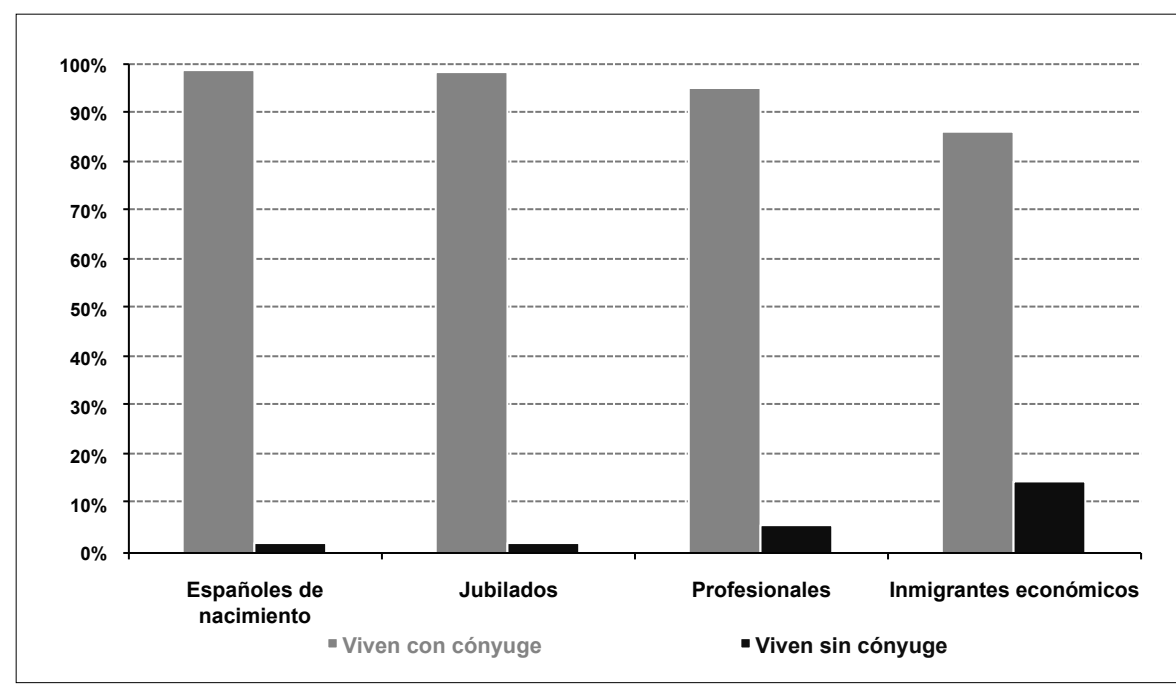

Fuente: Encuesta Nacional de Inmigrantes 2007.

Sin embargo, como se puede apreciar con claridad en el gráfico 2, los diferentes tipos de inmigrantes (casados) se encontraban en situaciones muy distintas en lo que se refiere a convivencia en pareja y separación de hecho del cónyuge. Se encontraban efectivamente separados de su cónyuge alrededor de 275 mil inmigrantes económicos casados (14\%), una situación que es casi 3 veces más probable para ellos que para los inmigrantes profesionales, 8 veces más probable que para los jubilados y 10 veces más probable que para los inmigrantes con nacionalidad española desde el nacimiento. En realidad, a la vista de estas cifras, sólo el grupo de los inmigrantes que hemos clasificado como económicos contiene un stock importante de reagrupantes potenciales del cónyuge. ${ }^{10}$ Los contingentes de inmigrantes con nacionalidad española desde el nacimiento y de jubilados que, estando casados, viven separados de hecho de sus cónyuges son muy reducidos ${ }^{11}$; entre los inmigrantes profesionales hay en cambio una proporción

\footnotetext{
${ }^{10}$ Hasta ahora, la legislación española no incluye a las parejas de hecho como objeto de la reagrupación familiar. Si, como es posible que ocurra en el futuro, un cambio legislativo incluyera a las parejas de hecho (y no sólo a los matrimonios) en la institución jurídica de la reagrupación familiar, sería necesario tener en cuenta a los solteros con sus parejas de hecho en los países de origen para estimar el número de reagrupantes de pareja potenciales.

${ }^{11}$ Debe tenerse en cuenta que estos dos tipos de inmigrantes son no sólo los que tienen una edad mayor, sino un tiempo de residencia en España más largo, considerablemente más largo de hecho entre los españoles de nacimiento (tabla 1).
} 
ligeramente mayor de casados separados $(5 \%)$, pero — dado que este grupo es de muy reducido- representa poco más de 7 mil individuos.

Por lo que se refiere a la convivencia con los hijos, también la situación es muy distinta entre los diferentes tipos de inmigrantes. En conjunto, casi dos tercios (64\%) de los inmigrantes han tenido algún hijo y un tercio $(36 \%)$ no, proporción que se reduce al $17 \%$ entre los jubilados. Al margen de los jubilados, que a este respecto se distinguen del resto de los inmigrantes debido a su edad y procedencia (países desarrollados), en la experiencia reproductiva de los inmigrantes pueden confluir dos procesos hasta cierto punto enfrentados: de una parte, muchos inmigrantes proceden de países con tasas de fecundidad más altas que las españolas; de otra, el proceso migratorio puede interferir en los planes reproductivos de una población que, siendo relativamente joven, podría haberse reproducido en mayor medida que la observada de no haber migrado.

En todo caso, para analizar las pautas de convivencia con los hijos (gráfico 3), conviene separar claramente a los inmigrantes económicos y los profesionales de los jubilados y los españoles con nacionalidad desde el nacimiento. A los jubilados, que son los que menos conviven con sus hijos, no hay por qué suponerles, en principio, intención de reagruparlos porque previsiblemente se trata en la gran mayoría de los casos de adultos con una vida independiente de la de sus padres. Los españoles de nacimiento con hijos,

Gráfico 3.

Convivencia con los hijos de los inmigrantes con hijos por tipo de inmigrantes

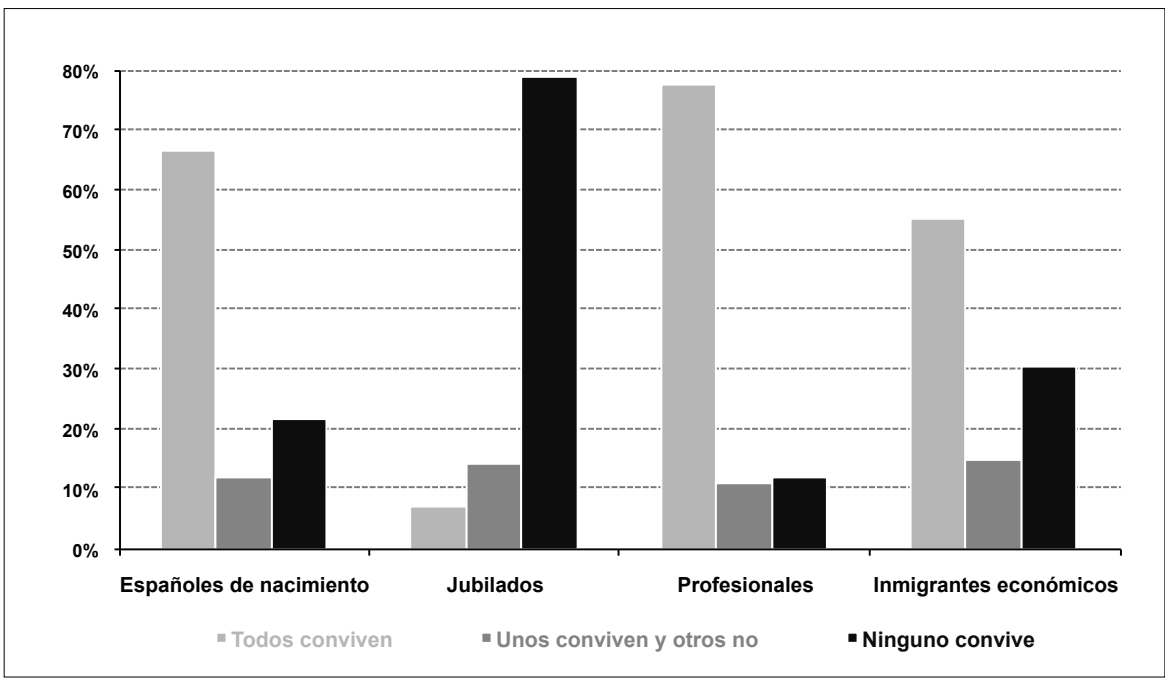

Fuente: Encuesta Nacional de Inmigrantes 2007. 
dos tercios de los cuales conviven con todos ellos, tienen una problemática específica en relación con la reagrupación de los hijos no convivientes muy distinta de la del resto de los inmigrantes. Por su parte, casi ocho de cada diez inmigrantes profesionales viven con sus hijos, siendo el grupo que presenta unas tasas más bajas de separación física de sus vástagos.

El grupo más interesante, tanto por su tamaño como por el grado de separación de los hijos, es el de los inmigrantes económicos: sólo un $55 \%$ de los que tuvieron hijos convive con todos ellos, con un $15 \%$ con algún hijo no conviviente y un $30 \%$ con todos los hijos habidos separados. Representan un contingente de 1,087 millones de reagrupantes potenciales de hijos, una cifra muy superior a los 34 mil profesionales o los 58 mil españoles de nacimiento que se encuentran en parecidas condiciones.

Gráfico 4.

Convivencia con el padre y la madre de los inmigrantes por tipo de inmigrantes

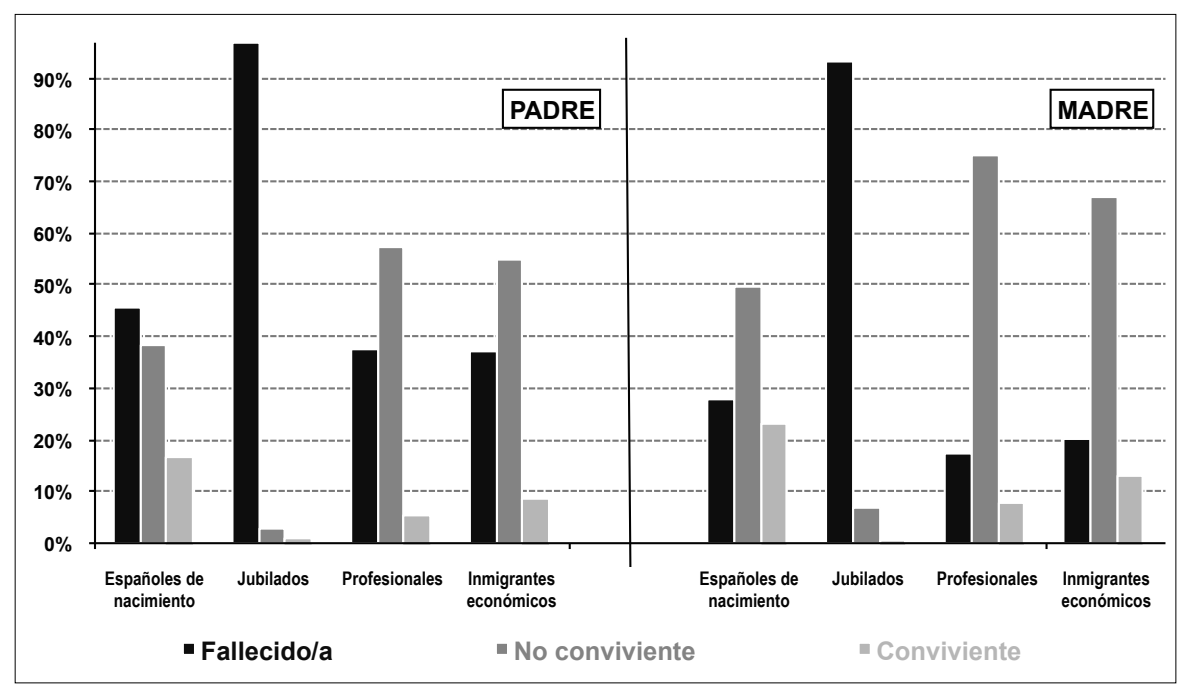

Fuente: Encuesta Nacional de Inmigrantes 2007.

Las pautas de convivencia con los padres (gráfico 4) reflejan también una realidad diversa para los diferentes tipos de inmigrantes que está marcada, ante todo, por la estructura de edad de cada grupo. La edad del inmigrante determina, en primer lugar, la probabilidad de supervivencia de sus padres y, subsiguientemente, la de convivir con ellos. Así, entre los inmigrantes jubilados la situación que predomina es la de ambos padres muertos, con una pequeña porción que no convive con uno de sus dos padres 
vivo. Los españoles de nacimiento, en cambio, son el tipo que mayores tasas de convivencia con los padres presenta, con una sexta parte de ellos conviviendo con su padre y casi una cuarta parte conviviendo con su madre. Los inmigrantes profesionales y los económicos presentan pautas similares: en ambos casos casi cuatro de cada diez inmigrantes ha perdido a su padre y dos de cada diez a su madre; también en ambos casos porcentajes próximos al $60 \%$ y al $70 \%$ viven separados de su padre o madre, respectivamente, con proporciones de convivencia con el padre inferiores al $8 \%$ y con la madre inferiores al $13 \%$.

Procede traducir ahora estos datos trasversales sobre la situación de convivencia de los inmigrantes a tasas de reagrupación familiar que reflejen la dinámica del proceso. Con los datos de la ENI 2007, se pueden reconstruir tasas de reagrupación para el caso de los cónyuges y los hijos ${ }^{12}$. En relación con los cónyuges, los comportamientos de reagrupación familiar son importantes, pues casi uno de cada seis (17\%) inmigrantes ha reagrupado, lo que supone, a su vez, uno de cada tres inmigrantes casados ${ }^{13}$. Por lo demás, la reagrupación es, con la migración conjunta, el comportamiento más frecuente, más practicado de hecho que el casamiento en España y que la separación de facto. Ahora bien, los comportamientos de reunificación son muy distintos entre los diferentes tipos de inmigrantes (tabla 4). Así, por ejemplo, los inmigrantes casados que tenían nacionalidad española desde el nacimiento se casaron en España muy mayoritariamente. Los jubilados, en cambio, son el tipo de inmigrantes que más migran de forma conjunta y simultánea con sus cónyuges. Entre los inmigrantes profesionales casados, lo usual es haberse casado en España. Y entre los inmigrantes económicos casados lo más habitual es haber reagrupado al cónyuge: por cada pareja que no ha reagrupado al cónyuge hay dos y medio que sí lo han hecho ${ }^{14}$. Eso no significa, sin embargo, que la realidad de los cónyuges no reagrupados no sea importante entre los inmigrantes económicos (15\% de todos los casados, en torno a los 280 mil individuos). Las proporciones de cónyuges no reagrupados entre el resto de los tipos de inmigrantes son mucho menores.

\footnotetext{
${ }^{12}$ Las tasas de reagrupación de los padres no se pueden estimar con precisión a partir de los datos de la ENI 2007 debido a falta de información. La información recogida por esta encuesta sólo incluye el momento de la llegada de los padres que conviven con la persona elegida, pero no se pregunta por la fecha de llegada de aquellos padres que, no conviviendo con el inmigrante elegido, viven en otra vivienda, otro municipio u otra provincia en España. En todo caso, la proporción de padres o madres convivientes es, como hemos señalado, muy reducida.

${ }^{13}$ Aquí entendemos la reagrupación conyugal en sentido fuerte, es decir, se consideran reagrupados los cónyuges que viven en el mismo hogar.

${ }^{14}$ Un análisis del proceso de reagrupación de las parejas con otra fuente datos ha concluido que la mayor parte de los colectivos inmigrantes que residen en España está cerca de completar la reagrupación y lo ha hecho, además, a un ritmo vertiginoso (González 2008).
} 
Tabla 4.

Reagrupación de los cónyuges de los inmigrantes en España (2007)

\begin{tabular}{lcccccc}
\hline & $\begin{array}{c}\text { Cónyuge no } \\
\text { reagrupado }\end{array}$ & $\begin{array}{c}\text { Cónyuge } \\
\text { reagrupado }\end{array}$ & $\begin{array}{c}\text { Migraron } \\
\text { juntos }\end{array}$ & $\begin{array}{c}\text { Casado } \\
\text { en España }\end{array}$ & $\begin{array}{c}\text { No } \\
\text { Casado }\end{array}$ & Total \\
\hline Españoles de nacimiento & 0,9 & 4,2 & 2,6 & 48,1 & 44,2 & 100 \\
Jubilados & 2,6 & 6,4 & 40,2 & 11,8 & 39,0 & 100 \\
Profesionales & 3,2 & 7,3 & 19,1 & 26,3 & 44,0 & 100 \\
Económicos & 7,6 & 18,2 & 15,4 & 8,3 & 50,4 & 100 \\
Total & 6,7 & 16,1 & 16,2 & 11,8 & 49,1 & 100 \\
\hline
\end{tabular}

Fuente: Encuesta Nacional de Inmigrantes 2007.

En general, los comportamientos de reagrupación de los hijos (tabla 5) ponen de manifiesto una intensidad menor que en el caso de los cónyuges, lo que sugiere que en estos procesos de reunificación familiar la pareja precede a los hijos. Una proporción de entre la quinta y la cuarta parte de los inmigrantes ha reagrupado a sus hijos (más de un tercio de todos los inmigrantes con hijos), frente a una sexta parte que no lo ha hecho (una cuarta parte de los inmigrantes con hijos). La reagrupación de los hijos está especialmente extendida entre los inmigrantes económicos. Sin embargo, es muy inusual entre los inmigrantes con nacionalidad española desde el nacimiento (quienes mayoritariamente han tenido sus hijos en España). Inmigrantes profesionales y jubilados han reagrupado a sus hijos en menor medida que los inmigrantes económicos: los primeros porque habiendo tenido a muchos de sus hijos en España no necesitaban reagruparlos y los segundos por la obvia razón de que sus edades sitúan a sus hijos en la fase adulta de su ciclo vital. En definitiva, son los inmigrantes económicos quienes con más intensidad reagrupan a sus hijos, pero también quienes, si exceptuamos a los jubilados, en mayor medida se encuentran con hijos aún pendientes de reagrupar.

Tabla 5.

Reagrupación de hijos de los inmigrantes en España (2007)

\begin{tabular}{lrrccc}
\hline No reagrupó & Reagrupó & $\begin{array}{c}\text { Hijos nacidos } \\
\text { en España }\end{array}$ & Sin hijos & Total \\
\hline Españoles de nacimiento & 1,6 & 2,3 & 61,0 & 35,1 & 100 \\
Jubilados & 42,9 & 15,9 & 26,1 & 15,1 & 100 \\
Profesionales & 4,4 & 17,8 & 38,7 & 39,1 & 100 \\
Económicos & 16,1 & 24,5 & 22,2 & 37,1 & 100 \\
Total & 16,1 & 22,3 & 25,7 & 35,8 & 100 \\
\hline
\end{tabular}

Fuente: Encuesta Nacional de Inmigrantes 2007. 


\section{LA DINÁMICA DE LA REAGRUPACIÓN FAMILIAR}

¿Qué factores impulsan la reagrupación familiar de cónyuges e hijos entre los inmigrantes asentados en España? Para responder a estas preguntas hemos procedido a realizar dos análisis de regresión logística independientes para cada uno de esos procesos. En el primer caso, la reagrupación de los cónyuges, nuestra variable dependiente confronta a aquellos inmigrantes que han reagrupado a sus esposos con aquellos otros que no lo han hecho; quedan fuera de este análisis, por tanto, los inmigrantes no casados, los que se casaron en España y los que migraron con su cónyuge. En el segundo caso, la reagrupación de los hijos, confrontamos a aquellos inmigrantes que han reagrupado a alguno de sus hijos con aquellos otros que no han reagrupado a ninguno de ellos. Esto significa que quedan excluidos del modelo estadístico los inmigrantes sin hijos y quienes los han tenido en España. Estos criterios dicotómicos para la variable dependiente no sólo son los requeridos por los modelos de regresión logística, sino que nos permiten controlar las comparaciones en orden a aislar los factores que específicamente dirimen los procesos de reagrupación entre la población susceptible de involucrarse en ellos.

En cuanto a las variables independientes, se han considerado el sexo, la edad (edad de llegada a España en el caso de la reagrupación de hijos), el nivel de estudios, el momento de llegada a España, el país de origen, la situación documental y el tipo de inmigrante. Con la inclusión de estas variables se pretenden captar los factores principales que promueven la reunificación familiar bajo la hipótesis de que es el grado de adaptación e integración del inmigrante en la sociedad anfitriona el que le permite la acumulación de recursos suficiente para hacer frente a la reagrupación de sus familiares. El periodo en que se llegó a España es una medida del tiempo de permanencia en el país receptor y así un indicador verosímil del éxito en la adaptación a él del inmigrante; la situación documental es una expresión consistente del grado de integración en la sociedad de acogida. Además, se incluyen como variables de control el sexo, la edad, el nivel educativo, el país de origen y el tipo de inmigrante.

A la vista de los resultados del análisis, podemos decir que entre la inmigración española el proceso de reagrupación del cónyuge depende de forma clara y fuerte del tiempo de permanencia y del grado de integración en nuestro país (tabla 6). Los coeficientes de regresión logística están claramente asociados tanto al momento de la llegada a España (cuanto antes se llegó y mayor tiempo de permanencia, mayor propensión a reunirse con el cónyuge) como a la situación documental (los inmigrantes con algún tipo de autorización para residir en España reagrupan más al cónyuge que los que se encuentran en situación de residencia irregular).

Es interesante señalar también que las mujeres, cuando han actuado como pioneras de la migración familiar, tienden a reagruparse con sus cónyuges notablemente más que los hombres; los jóvenes (de entre 25 y 29 años) más que los adultos y maduros; y los inmigrantes no económicos más que los económicos. Atendiendo al origen de los inmigrantes, son los inmigrantes procedentes de los países de Europa del Este, de Marruecos y de Ecuador y los países latinoamericanos no andinos los que más reagrupan al 
Tabla 6.

Reagrupación del cónyuge. Proporción observada que reagrupó y estimadores del modelo de regresión logística

\begin{tabular}{|c|c|c|c|c|c|}
\hline & Reagrupó & $\mathrm{N}$ & $\beta$ & & $\operatorname{Exp}(\beta)$ \\
\hline \multicolumn{6}{|l|}{ Sexo } \\
\hline Hombre (ref.) & $64,0 \%$ & 1969 & & & \\
\hline Mujer & $79,5 \%$ & 1471 & $1,187^{* * *}$ & $(0,104)$ & 3,28 \\
\hline \multicolumn{6}{|l|}{ Edad } \\
\hline $20-24$ & $74,9 \%$ & 167 & $0,747^{*}$ & $(0,291)$ & 2,11 \\
\hline $25-29$ & $73,4 \%$ & 424 & $0,998 * * *$ & $(0,248)$ & 2,71 \\
\hline $30-34$ & $70,0 \%$ & 593 & 0,673 ** & $(0,235)$ & 1,96 \\
\hline $35-39$ & $72,3 \%$ & 515 & 0,816 *** & $(0,236)$ & 2,26 \\
\hline $40-44$ & $74,7 \%$ & 384 & 0,726 ** & $(0,240)$ & 2,07 \\
\hline $45-49$ & $64,5 \%$ & 225 & 0,409 & $(0,255)$ & 1,51 \\
\hline $50-54$ & $69,3 \%$ & 116 & 0,231 & $(0,290)$ & 1,26 \\
\hline $55+$ (ref.) & $62,5 \%$ & 89 & & & \\
\hline \multicolumn{6}{|l|}{ Estudios } \\
\hline Primaria y menos & $67,9 \%$ & 1193 & 0,089 & $(0,157)$ & 1,09 \\
\hline Secundaria & $73,5 \%$ & 1673 & $0,377^{\star}$ & $(0,147)$ & 1,46 \\
\hline Superiores (ref.) & $68,3 \%$ & 520 & & & \\
\hline \multicolumn{6}{|l|}{ Llegada a España } \\
\hline Antes de 1997 (ref.) & $82,2 \%$ & 322 & & & \\
\hline $1997-2001$ & $74,3 \%$ & 1023 & $-0,765^{\star \star \star}$ & $(0,165)$ & 0,47 \\
\hline $2001-2007$ & $62,4 \%$ & 1168 & $-1,557^{\star * *}$ & $(0,171)$ & 0,21 \\
\hline \multicolumn{6}{|l|}{ País de origen } \\
\hline Países desarrollados & $72,2 \%$ & 167 & $-1,773^{*}$ & $(0,863)$ & 0,17 \\
\hline Europa del Este (ref.) & $79,1 \%$ & 424 & & & \\
\hline Ecuador & $71,9 \%$ & 593 & $-0,958^{\star * *}$ & $(0,186)$ & 0,38 \\
\hline Países Andinos & $60,9 \%$ & 515 & $-1,197^{\star * \star}$ & $(0,163)$ & 0,30 \\
\hline Resto de América Latina & $66,7 \%$ & 384 & $-0,985^{\star \star \star}$ & $(0,193)$ & 0,37 \\
\hline $\begin{array}{l}\text { Marruecos } \\
\text { Resto de África (sin }\end{array}$ & $78,3 \%$ & 225 & $-0,683^{\star \star *}$ & $(0,160)$ & 0,50 \\
\hline $\begin{array}{l}\text { Resto de Atrica (sın } \\
\text { Marruecos) }\end{array}$ & $49,5 \%$ & 116 & $-1,789^{* * *}$ & $(0,189)$ & 0,17 \\
\hline Asia y Oceanía & & & & & \\
\hline (no desarrollados) & $63,9 \%$ & 89 & $-1,698^{\star * *}$ & $(0,196)$ & 0,18 \\
\hline \multicolumn{6}{|l|}{ Situación documental } \\
\hline Con autorización (ref.) & $71,0 \%$ & 2195 & & & \\
\hline Pendiente & $60,7 \%$ & 102 & $-0,454^{*}$ & $(0,211)$ & 0,63 \\
\hline Sin documentos & $56,4 \%$ & 216 & $-0,638^{* * *}$ & $(0,157)$ & 0,53 \\
\hline \multicolumn{6}{|l|}{ Tipo de Inmigrante } \\
\hline No económicos (ref.) & $72,9 \%$ & 33 & & & \\
\hline Económicos & $70,5 \%$ & 2480 & $-0,776^{*}$ & $(0,378)$ & 0,46 \\
\hline \multirow{4}{*}{$\begin{array}{l}\text { Constante } \\
-2 \mathrm{LL} \\
\mathrm{R}^{2} \\
\mathrm{~N} \\
\text { cox\&Snell }\end{array}$} & & & $2,292^{\star \star \star}$ & $(0,422)$ & \\
\hline & & $433,96^{\star * *}$ & & & \\
\hline & & 0,148 & & & \\
\hline & & 2513 & & & \\
\hline
\end{tabular}

${ }^{*} p<0,05{ }^{* *} p<0,01{ }^{* * *} p<0,001$. Errores típicos entre paréntesis.

Fuente: Encuesta Nacional de Inmigrantes 2007. 
Tabla 7.

Reagrupación de los hijos. Proporción observada que reagrupó y estimadores del modelo de regresión logística

\begin{tabular}{|c|c|c|c|c|c|}
\hline & Reagrupó & $\mathrm{N}$ & $\beta$ & & $\operatorname{Exp}(\beta)$ \\
\hline Hombre (ref.) & $50,5 \%$ & 1521 & & & \\
\hline Mujer & $65,0 \%$ & 2265 & $0,735^{\star * *}$ & $(0,072)$ & 2,09 \\
\hline \multicolumn{6}{|l|}{ Edad } \\
\hline $20-24$ & $42,5 \%$ & 13 & $-0,463^{*}$ & $(0,232)$ & 0,63 \\
\hline $25-29$ & $52,2 \%$ & 1017 & $-0,141$ & $(0,169)$ & 0,87 \\
\hline $30-34$ & $63,0 \%$ & 625 & 0,234 & $(0,159)$ & 1,26 \\
\hline $35-39$ & $67,4 \%$ & 825 & 0,245 & $(0,158)$ & 1,28 \\
\hline $40-44$ & $73,2 \%$ & 651 & 0,495 ** & $(0,164)$ & 1,64 \\
\hline $45-49$ & $67,7 \%$ & 378 & $0,364^{*}$ & $(0,173)$ & 1,44 \\
\hline $50-54$ & $64,0 \%$ & 165 & 0,355 & $(0,193)$ & 1,43 \\
\hline $55+$ (ref.) & $33,8 \%$ & 112 & & & \\
\hline \multicolumn{6}{|l|}{ Estudios } \\
\hline Primaria y menos & $58,4 \%$ & 1277 & 0,100 & $(0,084)$ & 1,10 \\
\hline Secundaria & $58,4 \%$ & 1976 & $-0,220$ & $(0,117)$ & 0,80 \\
\hline Superiores (ref.) & $56,6 \%$ & 533 & & & \\
\hline \multicolumn{6}{|l|}{ Llegada a España } \\
\hline Antes de 1997 (ref.) & $60,1 \%$ & 229 & & & \\
\hline $1997-2001$ & $64,7 \%$ & 1479 & $-0,344^{*}$ & $(0,174)$ & 0,71 \\
\hline $2001-2007$ & $53,0 \%$ & 2078 & $-0,884^{\star * *}$ & $(0,176)$ & 0,41 \\
\hline \multicolumn{6}{|l|}{ País de origen } \\
\hline Países desarrollados & $30,3 \%$ & 13 & $-1,856$ ** & $(0,680)$ & 0,16 \\
\hline Europa del Este (ref.) & $68,6 \%$ & 1017 & & & \\
\hline Ecuador & $61,4 \%$ & 625 & $-0,671^{\star * *}$ & $(0,119)$ & 0,51 \\
\hline Países Andinos & $56,7 \%$ & 825 & $-0,845^{\star \star *}$ & $(0,101)$ & 0,43 \\
\hline Resto de América Latina & $70,5 \%$ & 651 & $-0,268^{*}$ & $(0,112)$ & 0,76 \\
\hline Marruecos & $78,8 \%$ & 378 & 0,068 & $(0,162)$ & 1,07 \\
\hline Resto de África (sin Marruecos) & $35,6 \%$ & 165 & $-1,803^{\star * *}$ & $(0,191)$ & 0,16 \\
\hline Asia y Oceanía (no desarrollados) & $55,4 \%$ & 112 & $-0,837^{\star \star *}$ & $(0,179)$ & 0,43 \\
\hline \multicolumn{6}{|l|}{ Situación documental } \\
\hline Con autorización (ref.) & $66,6 \%$ & 3018 & & & \\
\hline Pendiente & $53,8 \%$ & 260 & $-0,425^{\star * *}$ & $(0,126)$ & 0,65 \\
\hline Sin documentos & $47,0 \%$ & 508 & $-0,622^{\star * *}$ & $(0,106)$ & 0,54 \\
\hline \multicolumn{6}{|l|}{ Tipo de Inmigrante } \\
\hline No económicos (ref.) & $42,3 \%$ & 120 & & & \\
\hline Económicos & $60,4 \%$ & 3666 & $-1,693^{\star * *}$ & $(0,285)$ & 0,18 \\
\hline Constante & & & $2,818^{\star \star \star}$ & $(0,327)$ & \\
\hline$-2 \mathrm{LL}$ & & 531 & & & \\
\hline $\mathbf{R}_{\text {cox\&Snell }}^{2}$ & & 0,12 & & & \\
\hline $\mathbf{N}^{\text {CoxdSnell }}$ & & 3786 & & & \\
\hline
\end{tabular}

${ }^{*} p<0,05{ }^{* *} p<0,01{ }^{* * *} p<0,001$. Errores típicos entre paréntesis

Fuente: Encuesta Nacional de Inmigrantes 2007. 
cónyuge, frente a los africanos no marroquíes, los andinos no ecuatorianos, los asiáticos y los procedentes de los países desarrollados, que registran menores tasas de reagrupación del cónyuge. Para interpretar estas diferencias por origen hay que considerar los factores asociados tanto a la distancia geográfica (caso de los marroquíes) como a la facilidad de movimientos (caso probable de los rumanos, que constituyen el grueso de los procedentes de los países de Europa oriental) o a la escasez de recursos (caso de los africanos no marroquíes). Los argumentos de la distancia o de la falta de recursos no funcionan, obviamente, para los inmigrantes de los países desarrollados, cuyo estatus socioeconómico es, casi por definición, muy diferente al del resto de los inmigrantes.

La dinámica de reagrupación de los hijos (tabla 7) se produce con arreglo a pautas relativamente similares a la de los cónyuges. Porque también el tiempo transcurrido desde la llegada a España del inmigrante y su grado de integración en el país (medido aquí a través del estatus legal) operan de manera favorable a la reagrupación de los hijos. Los inmigrantes más recientes, particularmente aquellos que han migrado después del año 2001, presentan una menor probabilidad de haber reagrupado a sus hijos que los que tienen más permanencia en el país anfitrión. Asimismo, entre los inmigrantes llegados a España, el grado de regularización de la situación residencial aumenta de forma significativa las probabilidades de haber reagrupado a los hijos.

Por otra parte, también las mujeres tienden más a reagrupar a los hijos que los hombres y los inmigrantes no económicos más que los económicos, no estableciendo el nivel educativo diferencias significativas. Respecto a la edad, los jóvenes de entre 25 y 29 años y los adultos de entre 40 y 44 años parecen haber reagrupado más a sus hijos que los del resto de las edades. Y, en cuanto al país de origen, son los inmigrantes de la Europa del este quienes más propenden, cuando se mantiene el resto de los factores constantes, a reagrupar a los hijos, aunque también los ecuatorianos, los inmigrantes procedentes de la zona andina y los asiáticos presentan una propensión relativamente alta a la reagrupación. Los inmigrantes marroquíes no se diferencian significativamente de los europeos orientales. Los inmigrantes procedentes de los países desarrollados (entre los que abundan los jubilados) y los africanos no marroquíes son, en cambio, los que en menor medida reagrupan a los hijos. Por lo tanto, se aplican también a la reagrupación de los hijos parecidas consideraciones a las que hemos hecho sobre el peso de la distancia y la facilidad de movimientos en relación con la reagrupación de los cónyuges, incluida la salvedad relativa a los inmigrantes procedentes de países desarrollados (con alto estatus socioeconómico pero baja probabilidad de reagrupar).

\section{Conclusiones}

El presente trabajo presenta los resultados de un análisis general de las familias de los inmigrantes instalados en España. La reciente experiencia migratoria española ha generado ya un cuerpo de investigación considerable y riguroso que ha tratado muchas de sus principales dimensiones, aunque posiblemente no se haya ocupado con la debida 
profundidad de las formas familiares de convivencia de los inmigrantes. Para tratar de paliar esta carencia, nos hemos centrado en tres objetivos específicos de investigación: las formas de convivencia de los inmigrantes en términos del tamaño y la estructura de los hogares; la composición de los hogares en términos de los familiares nucleares presentes y ausentes en ellos; y la dinámica de reagrupación familiar que ha contribuido a esas estructuras domésticas en términos de los factores que promueven e inhiben la incorporación de los cónyuges y los hijos a los hogares formados en España.

En parte, la oportunidad de investigar las formas familiares de los inmigrantes en España se deriva directamente de la disponibilidad de nuevas fuentes de información para estudiar este fenómeno. En este sentido, nuestro análisis de las familias inmigrantes en España se basa, en lo fundamental, en la información que proporciona la Encuesta Nacional de Inmigrantes 2007, la fuente de datos más completa para estudiar de forma integral el fenómeno de la reciente inmigración en nuestro país. Dicha fuente suministra, en efecto, una información tan valiosa como abundante sobre múltiples dimensiones del fenómeno migratorio, incluidas las referentes a las características familiares y domésticas de los inmigrantes y a sus trayectorias migratorias. Los datos de la Encuesta, realizada en 2007, tienen además una relativa actualidad que hace de ellos un instrumento idóneo para los fines propuestos.

Las formas familiares de los inmigrantes en España se caracterizan, básicamente, por un alto grado de concentración doméstica (un tamaño medio del hogar elevado) y por sus estructuras de convivencia relativamente complejas (abundancia de hogares en los que corresiden familiares que no pertenecen a sus núcleos constitutivos). Ambas características son típicas de otras poblaciones con una experiencia migratoria reciente; al tiempo, distinguen a estos hogares inmigrantes de los formados por la población autóctona en la sociedad anfitriona. Ahora bien, estas formas familiares están claramente asociadas a los diferentes tipos de inmigrantes. Por una parte, los hogares de los inmigrantes jubilados, los de los inmigrantes con nacionalidad española desde el nacimiento y los de los inmigrantes con perfil profesional son relativamente similares a los de los españoles de parecida condición social y demográfica. Por otra, los hogares de los inmigrantes económicos -el tipo que representa a una población mayor-son definitivamente más numerosos y complejos que los de los españoles. Puesto que el propio proceso migratorio tiende a dividir las unidades domésticas de los que en él participan, el mayor tamaño y complejidad de estos hogares inmigrantes hay que explicarlo por el funcionamiento de las redes familiares y por los procesos de reagrupación familiar; aunque la estructura de edades y la pauta de asociación doméstica de los inmigrantes con los españoles con los que en muchos casos comparten residencia también contribuyen a dar cuenta del tamaño y la complejidad de sus hogares.

Estas formas de convivencia de los inmigrantes suponen, particularmente entre los inmigrantes económicos, proporciones de alguna entidad de matrimonios que viven separados de hecho, porcentajes mucho mayores de padres que no conviven con sus hijos y un volumen relativamente más elevado aún de hijos adultos que viven alejados de sus padres. Eso implica que los movimientos de reagrupación familiar de los cón- 
yuges se han producido con mucha más intensidad y velocidad que los de los hijos y también que el número potencial de hijos agrupables es considerablemente mayor que el de cónyuges.

Pese a que entre los inmigrantes asentados en España el proceso de reagrupación familiar de los cónyuges ha sido más rápido e intenso que el de los hijos, los factores que impulsan la reunificación de familiares son relativamente similares en ambos casos. De particular importancia a este respecto son la adaptación del inmigrante a la sociedad de acogida (medida por el tiempo de permanencia en el país) y su grado de integración (medido por la situación documental). Ambos funcionan en el sentido esperable: a mayor adaptación e integración en el destino migratorio, más probables resultan los movimientos de reagrupación familiar, aunque ciertamente hay también otros elementos, como la distancia geográfica o la disponibilidad de recursos económicos, que asimismo desempeñan un papel importante en dichos procesos.

Los resultados que hemos alcanzado ofrecen así una perspectiva amplia de las formas de convivencia doméstica de los inmigrantes en España que, por lo que sabemos, no se ha desarrollado hasta el momento presente en nuestro país con el nivel de detalle que aquí mostramos. Por tanto, y en la medida en que este producto de investigación tiene un carácter novedoso, creemos que será de utilidad para afinar la descripción de las formas familiares de los inmigrantes en España, depurar las interpretaciones de su situación familiar y perfilar futuras hipótesis sobre la estrecha interacción entre las dinámicas familiares y las trayectorias migratorias que rige la experiencia siempre compleja de la migración. Por lo demás, los datos y argumentos que ofrecemos en este trabajo pueden asimismo contribuir a orientar el trabajo de los diseñadores de las políticas públicas migratorias en nuestro país, en particular de las que tienen por objeto regular la reagrupación familiar.

\section{ReFERENCIAS BibLIOGRÁFICAS}

Arango, J. 2004. "La inmigración en España a comienzos del siglo XXl”. Pp. 161-186 en J. Leal (ed.), Informe sobre la situación demográfica en España. Madrid: Fundación Fernando Abril Martorell.

Blanco, C. 2000. Las migraciones contemporáneas. Madrid: Alianza Editorial.

Booth, A., A.C. Crouter y N. Landale. eds. 1997. Immigration and the family: research and policy on U.S. Immigrants. Mawhaw: Lawrence Erlbaum.

Borjas, G.J. y S.G. Bronars. 1991. "Immigration and the Family." Journal of Labor Economics. 9: 123-148.

Cabré, A., C. Cortina y A. Esteve. 2009. "¿Con quién se unen los latinoamericanos en España? Respuestas a partir de tres fuentes demográficas." Notas de Población. 86: 19-38.

Castro, T. 2002. "Consensual Unions in Latin America: Persistence of a Dual Nuptiality System." Journal of comparative family studies. $33:$ 35-55. 
Cebolla, H. y M. Requena. 2009. "Los inmigrantes marroquies en España". Pp. 251-287en D. Reher y M. Requena (eds.), Las múltiples caras de la inmigración en España. Madrid: Alianza Editorial.

Cortina, C., A. Esteve y A. Domingo. 2006. "Crecimiento y singularidades demográficas de los matrimonios de extranjeros en España." Migraciones 20: 75-105.

Cortina, C., A. Esteve y A. Domingo. 2008. "Marriage patterns of foreign born population in a new country of immigration: the case of Spain." International Migration Review. 42: 877-902.

Esteve, A. y C. Cortina. 2009. Pathways to family formation of international migrants. Ponencia presentada en el XXVI Congreso Internacional de Población (IUSSP). 27 de septiembre a dos de octubre, Marrakech (Marruecos).

Falicov, C. J. 2008. "Immigrant Family Process". Pp. 280-300 en F. Walsh (eds.), Normal Family Processes. Growing Diversity and Complexity. Nueva York: The Guildford Press.

Fix, M., W. Zimmermann y J.S. Passel. 2001. The Integration of Immigrant Families in The United States. Washington: The Urban Institute.

Garrido, L. 2005. “La inmigración en España”. Pp. 127-164, en J. J. González y M. Requena (eds.), Tres décadas de cambio social en España. Madrid: Alianza Editorial.

González, A. 2008. "La reagrupación familiar en España. Algunas cifras para el debate”, Pp. 120-137, en E. Aja, J. Arango y J. Oliver (eds.), La inmigración en la encrucijada. Anuario de la inmigración en España. Barcelona, Fundació CIDOB.

González, M. 2007. "El régimen de la reagrupación familiar”. Pp. 127-142 en E. Argullol (dir.), Inmigración y transformación social en Cataluña. Vol. II. Estudio jurídico comparado. Madrid: Fundación BBVA.

Instituto Nacional de Estadística. 2009. Encuesta Nacional de Inmigrantes 2007: una monografía. Madrid: Instituto Nacional de Estadística.

Izquierdo, A. ed. 2003. Inmigración: mercado de trabajo y protección social en España. Madrid: Consejo Económico y Social.

Jasso, G. y M. Rosenzweig 1986. "Family Reunification and the Immigration Multiplier: U.S. Immigration Law, Origin Country Conditions, and The Reproduction of Immigrants." Demography. 23: 291-311.

Kofman, E. 2004. "Family-Related Migration: A Critical Review of European Studies." Journal of Ethnic and Migration Studies 30(2): 243-262.

López de lera, D. 2006. "El impacto de la inmigración extranjera en las regiones españolas". Pp. 233372en J. A. Fernández Cordón, y J. Leal (eds.), Análisis territorial de la demografía española. Madrid: Fundación Abril Martorell.

Massey, D. 1987. "Social Structure, Household Strategies and Cumulative Causation of Migration." Population Index. 56:3-26.

Massey, D. y J. A. Phillips. 1999. "Engines of Inmigration: Stocks of Human and Social Capital in Mexico." Social Science Quarterly. 81: 33-48. 
Massey, D., J. Durand y F. Riosmena. 2006. "Capital Social, política social y migración desde comunidades tradicionales y nuevas comunidades de origen en México". Revista Española de Investigaciones Sociológicas. 116: 97-121.

Pascual, A. (dir.). 2007. Redes sociales de apoyo. La inserción de la población extranjera. Bilbao: Fundación BBVA.

Pedone, C. y S. Gil. 2008. "Maternidades transnacionales entre América Latina y el Estado español. El impacto de las políticas migratorias en las estrategias de reagrupación familiar". Pp. 149-176 en C. Solé, S. Parella y L. Cavalcanti (eds.), Nuevos retos del transnacionalismo en el estudio de las migraciones. Madrid: OPI-Ministerio de Trabajo e Inmigración.

Reher, D., L. Cortés, F. González, M. Requena, M.I. Sánchez, A. Sanz y M. Stanek. 2008. Informe Encuesta Nacional de Inmigrantes (ENI-2007), Madrid: Instituto Nacional de Estadística.

Reher, D. y M. Requena. 2009a. "The National Immigrant Survey of Spain: A new data source for migration studies in Europe." Demographic Research. 20: 253-278.

Reher, D. y M. Requena. 2009b. "Introducción: el impacto de la inmigración en la sociedad española". Pp. 7-19 en D. Reher y M. Requena (eds.), Las múltiples caras de la inmigración en España. Madrid: Alianza Editorial.

Reher, D. y B. Sánchez Alonso. 2009. "Argentina y España: siglo y medio de intercambios migratorios". Pp. 77-115 en D. Reher y M. Requena (eds.), Las múltiples caras de la inmigración en España. Madrid: Alianza Editorial.

Requena, M. 1999. "Pautas contemporáneas de evolución de los hogares en España". Revista Internacional de Sociología 22: 33-65.

Requena, M. 2004. "Tamaño y composición de los hogares y familias en España". Pp. 135-159 en J. Leal (coord.) Informe sobre la situación demográfica en España. Madrid: Fundación Fernando Abril Martorell.

Requena, M. 2009. "Los cambios familiares en España y sus implicaciones", Revista del Ministerio de Trabajo e Inmigración (en prensa).

Requena, M. y D. Reher. 2009. "La reciente experiencia inmigratoria en España”. Pp. 289-321en D. Reher y M. Requena (eds.), Las múltiples caras de la inmigración en España: Madrid: Alianza Editorial.

Roig, M. y T. Castro. 2007. "Childbearing Patterns of Foreign Women in a New Immigration Country: The Case of Spain". Population (English edition). 62: 351-380; Population (Édition française) 62: 419-446.

Rumbaut, R.G. 1997. "Ties that Bind: Immigration and Immigrants Families in the United States". Pp. 3-46 en A. Booth, A.C. Crouter y N. Landale (eds.), Immigration And The Family: Research And Policy On U.S. Immigrants. Mawhaw: Lawrence Erlbaum.

Suárez-Orozco, C., I. Todorova. y J. Louie. 2002. "Making up for lost time: The experience of separation and reunification among immigrant families." Family Process. 41: 625-643.

Suárez-Orozco, M, C. Suárez-Orozco y D.B. Qin (eds.). 2005. The New Immigration: An Inter-disciplinary reader. Nueva York: Taylor \& Francis Group. 
Van Hook, J. y J.E. Glick. 2007. "Immigration and Living Arrangements: Moving Beyond Economic Need versus Acculturation." Demography. 44: 225-249.

MIGUEL REQUENA es Catedrático de Sociología en el Departamento de Sociología II (Estructura Social) en la UNED y miembro del Grupo de Estudios "Población y Sociedad". Ha sido profesor en la Universidad Complutense, miembro del Gabinete Técnico del Centro de Investigaciones Sociológicas, Doctor Vinculado al Instituto de Estudios Sociales Avanzados del Consejo Superior de Investigaciones Científicas, Senior Associate Member en St Antony's College (Oxford) y Visiting Professor en Princeton University. Su investigación se ha centrado en la sociología y la demografía de la familia, la sociología de la edad, la sociología de la estructura y la estratificación social y los procesos contemporáneos de cambio social.

MARÍA SÁNCHEZ-DOMÍNGUEZ es ayudante técnico posdoctoral de investigación en la Universidad Complutense de Madrid dentro del proyecto de investigación La Encuesta Nacional de Inmigrantes (ENI): Explotación con perspectivas comparativas nacionales e internacionales (CSO2008-03616). Licenciada y Doctora en Sociología. Sus áreas principales de investigación son: migraciones internacionales, procesos de emparejamiento (endogamia y exogamia) de la población inmigrante, integración social y familia.

RECIBIDO: 22/06/2010

ACEPTADO: $14 / 10 / 2010$ 